\title{
Effect of grape skin powder extract addition on functional and physicochemical properties of marshmallow
}

\author{
Eugenia Covaliov, Natalia Suhodol, Aurica Chirsanova, \\ Tatiana Capcanari, Carolina Grosu, Rodica Siminiuc
}

\author{
Technical University of Moldova, Chisinau, Moldova
}

Keywords:

Grape

Skin

Marshmallow

Antioxidant

Phenolic

\section{Article history:}

Received

09.03.2021

Received in revised

form 06.06.2021

Accepted

30.06 .2021

\section{Corresponding}

author:

Eugenia Covaliov

E-mail:

eugenia.boaghi@

toap.utm.md

DOI:

$10.24263 / 2304-$

974X-2021-10-2-10

\begin{abstract}
Introduction. The present research evaluated the effect of grape skin powder extract addition on functional and physicochemical properties of marshmallow.

Materials and methods. To assess the effect of grape skin on marshmallow quality, alcoholic grape skin extracts (GSE) were prepared and introduced in different amounts in marshmallow recipes. The functional properties of marshmallows were estimated by determining the total polyphenol content and antioxidant activity. The microbiological stability of the product was assessed by using agar meat broth. Molds proliferation and morphology of cells from single colonies was studied under microscope.
\end{abstract}

Results and discussion. The effects of grape skin extract (GSE) on marshmallow quality were evaluated. The marshmallow physicochemical properties in terms moisture and sugar content were affected by GSE incorporation. A directly proportional relationship was observed between the addition of GSE and the moisture content of the marshmallow samples, registering an increase from 15.02 to $15.58 \%$ for the samples with $1 \%$ and $3 \%$ GSE respectively. The sugar content varied in the limits of 14.05 $14.21 \%$, being higher for the samples with an increased amount $h$ GSE. Total phenolic content of GSE and marshmallow samples with added GSE was determined as 27.39, 5.11 (1\% GSE marshmallow), 6.46 (2\% GSE marshmallow) and 7.89 (3\% GSE marshmallow) $\mathrm{mg} / \mathrm{g}$ gallic acid (GAE), respectively. Hydrogen peroxide inhibition capacity and DPPH radical scavenging of marshmallows had increased in proportion to rising GSE level. Antioxidant activity of marshmallows containing 3\% GSE was found to be higher $(35.72 \%)$ than others. The addition of GSE significantly affected the marshmallows color parameters, as the amount of grape skin increased, a more intense purple coloration was observed. The marshmallow containing 2\% GSE was most appreciated in terms of sensorial properties. The GSE addition had inhibitory effects on mold population during storage, a higher degree of mold growth reduction $(p<0.05)$ being observed in the sample with 3\% GSE after 7 days of storage.

Conclusions. The addition of grape skin extract in marshmallow formulation increased the biological value in terms of antioxidant activity and total phenol content, and the consumers' acceptancy. 


\section{- Food Technology -}

\section{Introduction}

It is known that the main wine making by-product is represented by grape pomace, that constitutes about $15 / 20 \%$ of the total grape weight (around 7 million tons) (Oiv-StatisticalReport-on-World-Vitiviniculture-2018.Pdf, n.d.). The nutritional quality of grape pomace appears rich in sugars, vitamins, minerals, polyphenols and other macromolecules which are of high interest for the food industry (Bordiga et al., 2019). Due to the rich nutritional compositions and beneficial effects of grape skin on human health demonstrated by numerous researches (Abarghuei et al., 2010; Iora et al., 2015), the interest for the development of new foods based on its use as cookies, various fillings for pastries, drinks, etc. has increased (Acun et al., 2014). Numerous researches have been carried out related to the capitalization of these industrial wastes, including as animal feed, additions in flour mixes for pastry products, ingredients for candy production, sources of biologically active substances with antioxidant potential, etc. (Cappa et al., 2015; Otero-Pareja et al., 2015). The positive effect of grape skin flour on total fibre and ash contents in yogurts and other fermented analogs has been demonstrated (dos Santos et al., 2017). Use of grape skin powder in functional cookies increased their that protein and fiber content and showed higher antioxidant potency, higher total phenol and higher retention of hardness during storage (Theagarajan et al., 2019).

The research carried out particularly emphasizes the content of polyphenols in grape skins and their antioxidant capacity. Depending on the grape variety, the total polyphenol content varies within $>20 \mathrm{mg}$ GAE/g of grape skin dry matter for white grapes and $>70 \mathrm{mg}$ GAE/g of grape skin dry matter for red grapes (Cvietko Bubalo et al., 2016; Katalinić et al., 2010), flavonols, catechins and anthocyanins being the main phenolic compounds detected (Antoniolli et al., 2015; Caldas et al., 2018). Sun and others have investigated the antioxidant effects of these compounds, and their antitumor and antimetastatic role in preventing breast cancer (Sun et al., 2012), and Jarivapamornkoon and colab. showed the positive effect of red grape skin extract on protein glycation (Jariyapamornkoon et al., 2013).

Often to give color and to extend the products shelf life, especially sweet products, manufacturers use dyes and antioxidants of synthetic origin such as carmuazine and tartrazine, etc. which are more intense and stable during products storage (Caleja et al., 2017). However taking into account current trends in the food industry, the need of this researches results from the FAO/WHO strategy of substituting synthetic substances (additives, texture agents, etc.) with natural bioactive components, which is a way to increase food safety and quality, a benchmark in optimized nutrition (McGuire, 2013; Taghvaei et al., 2015) and of diminishing the food waste level (Gustavsson et al., 2011).

Withal, the replacement of synthetic substances with natural ones resulting from the vines processing is a strategic problem, because, unlike synthetic ones, natural substances have fragile molecules, sensitive to food matrix, storage conditions, etc. However, the antiradical and microbiostatic activity of grape skin extracts, rich in polyphenols, is a promising source of alternative solutions for their use in order to replace certain synthetic food preservatives (Katalinić et al., 2010; Shin et al., 2010).

However, as far as is known, the grape variety, food matrix, ingredients and investigated quality parameters in each study are different from those presented in the current study. In the present study the marshmallow prototype was chosen as the food matrix. Marshmallow is a sweet product preferred by all categories of the population, but especially children have always preferred them (Ungure et al., 2013). Due to the fact that many researchers have demonstrated the positive effects of incorporating grape skin into various food products, but less in marshmallows, hence the purpose of the present research is to evaluate the effect of grape skin powder extract addition on functional and physicochemical properties of marshmallow. 


\section{- Food Technology}

\section{Materials and method}

\section{Materials and chemicals}

A standard recipe of marshmallow was used. The ingredients for the marshmallow production were as (Yurchenko et al., 2020): egg whites, agar-agar, sugar, citric acid and grape skin powder.

\section{Grape skin extracts}

In order to obtain grape skin extract (GSE), pomace resulting from the production of Merlot wine was used. The grape pomace was initially dried at $50 \pm 2{ }^{\circ} \mathrm{C}$ until its moisture content reached $5 \%$ value. The pomace was then blown to separate the skin from the seeds. The skin of the grapes was minced and hydroalcoholic extracts $(50 \%$ EtOH, 1:10) were prepared.

\section{Marshmallow production}

The marshmallow was prepared using agar-agar, egg whites, sugar, apple puree and water (Yurchenko et al., 2020), with the addition of grape skin hydroalcoholic extract (1.0\% and $2.0 \%, 3.0 \%$ of total weight).

The technological process of preparing marshmallows begins with the preparation of apple puree, which involves peeling apples, cutting them into pieces and boiling them with a little water, over a moderate heat until the consistency of the apple pieces is soft. The apple pieces are minced with the a blender and an amount of $30 \%$ of sugar is then added. The mixture is put on a moderate heat and mixed until the sugar crystals are completely dissolved.

The apple puree, GSE and the egg whites are placed in the bowl of the mixer and the mixture is foamed starting from the low speed to the higher speed of the mixer. The mixture is foamed until the hard peaks are obtained.

Separately the sugar syrup with agar is prepared: the agar is mixed with water and sugar and put on the fire, stirring constantly until boiling. From the moment of boiling, the syrup is kept on the fire for another 5 minutes until the thin thread syrup is obtained. The syrup then is added to the mixture of egg white and apple puree while the mixer continues to foam the composition. The mixture is beaten until a shiny and firm composition is obtained. Using a pastry bag, the marshmallows are shaped and then allowed to dry for 3-6 hours.

\section{Grape skin powder and marshmallow properties}

\section{Moisture content}

The moisture content of grape skin powder and marshmallow samples was determined by oven drying, according to the AOAC, 2005; method 930.15 (Horwitz, 2005).

\section{Sugar content}

The reducing sugars concentration of marshmallows was analyzed by Benedict's, Bertrand's and Fehling standard procedures (Kumar et al., 2014). 


\section{Titratable acidity (TA)}

The TA was determined by titration to $\mathrm{pH} 8.1$ with $0.1 \mathrm{M} \mathrm{NaOH}$. Phenolphthalein $(0.1 \%)$ was used as an indicator (Mutlu et al., 2018).

\section{Total Polyphenol content (TPC)}

The total polyphenol content in grape skin powder and marshmallow samples was determined by Folin Ciocalteu method described by Makkar et al. (2003) (Makkar, 2003).

\section{Antioxidant activity (AA)}

1,1-Diphenyl-2-picryl-hydrazyl (DPPH) solutions were prepared in methanol. The sample solutions (Grape skin and marshmallow hydroalcoholic extracts $100 \mu \mathrm{L}$ ) at varying concentrations $(0.1-10 \mathrm{mg} / \mathrm{mL})$ was added to a $0.1 \mathrm{mM}$ methanolic solution of DPPH $(3.9 \mathrm{ml})$ and shaken vigorously. The reaction tubes, in triplicates, were kept in dark, at $30 \mathrm{C}$ for $30 \mathrm{~min}$. Spectrophotometric measurements were done at $517 \mathrm{~nm}$ using Hach Lange DR 5000 spectrophotometer. The data are mean $\pm \mathrm{SD}$ (Sharma et al., 2009).

\section{Hydrogen peroxide scavenging activity assay}

Hydrogen peroxide inhibition capacity of the GSE and marshmallow samples was determined by replacement titration. Aliquot of $1 \mathrm{ml}$ of sample and $1 \mathrm{ml}$ of hydrogen peroxide solution $(0.1 \mathrm{mM})$ were mixed. Then 2 drops of ammonium molybdate $(3 \%)$ solution were added, followed by. $10 \mathrm{ml}$ of sulfuric acid (2M) and $7 \mathrm{ml}$ of potassium iodide (1.8M). The obtained solution was left to interact for 20 minutes, then titrated with sodium thiosulphate $(5.09 \mathrm{mM})$ until the yellow color disappeared. In parallel, the control sample (without extract) was analysed. The thiosulphate volume expended for titration were record (V1-for sample with GSE, and $\mathrm{V}_{0}$ - for control sample). Percentage of hydrogen peroxide inhibition was calculated as (Nagulendran et al., 2007):

$$
\% \mathrm{H}_{2} \mathrm{O}_{2} \text { Inhibition }=\frac{\left(V_{0}-V_{1}\right)}{V_{0} \times 100}
$$

\section{Color parameters assessment}

In the food science and technology color is traditionally represented using the CIE 1976 $L^{*} a^{*} b *$ or CIELAB color space (Goñi et al., 2017). The influence of the addition of GSE on the chromatic parameters of the marshmallow was evaluated with using the tristimulus CieLab colorimeter. For each sample, individual color parameters $L * a *$ and $b *$ were quantified.

Color changes was measured as the modulus of the distance vector between the initial color values and the actual color coordinates. This concept is called total color difference $(\Delta \mathrm{E})$. The total color difference indicates the magnitude of the color difference between the control samples and those investigated (Ly et al., 2020).

\section{Microbiological analysis}

For each sample, marshmallows were analyzed after 1,3 and 7 days of storage at $6 \pm 2{ }^{\circ} \mathrm{C}$. Appropriate dilutions were made and pour-plated onto selective media. In order to determine the microbiological stability of the product, determinations were performed on agar meat broth for molds proliferation. Each sample was inoculated in triplicate. The selectivity of the growth conditions was confirmed by morphology of cells from single colonies under microscope (Jung et al., 2016). 


\section{Sensory evaluation}

In order to perform the organoleptic test, marshmallows were prepared one day in advance. Twelve panelists (aged 24 to 69 years old), participated in this study and appreciated the quality of marshmallows based on the 9-point hedonic scale from "dislike extremely" to "like extremely". For the present research, first was discussed the main quality characteristics of marshmallow. The marshmallow samples were investigated for appearance, texture, taste, flavor, color and overall acceptance (Cano-Lamadrid et al., 2018).

\section{Statistical analysis}

All experiments were carried out in triplicate. The results are given as mean standard deviation (SD). Student's t-test was used for comparison between two means. A difference was considered statistically significant when $\mathrm{p} \leq 0.05$.

\section{Results and disscution}

\section{Physico-chemical parameters}

Marshmallow samples showed different values of the studied parameters depending on the added GSE concentration.

The following physico-chemical indices were investigated in the experimental samples: moisture content, reducing sugars content and total titratable acidity. The obtained results are illustrated in Table 1.

The obtained results (Table 1) indicate that with an increase in the mass fraction of grape skin extract, the moisture content of marshmallows increases as well from $15.05 \%$ for the control sample to $15.68 \%$ for the sample with $3 \%$ GSE addition. This increase in moisture can be explained by the increase, in the same time, of reducing sugars (glucose, fructose) and dietary fibers amount that lead to the increase of marshmallow water binding capacity (Ergun et al., 2010).

Physico-chemical characteristic of the marshmallow

Table 1

\begin{tabular}{|l|c|c|c|}
\hline \multicolumn{1}{|c|}{ Sample } & Moisture,\% & Reducing sugar,\% & $\begin{array}{c}\text { Titratable acidity, } \\
\mathbf{~ m E q} / \mathbf{l}\end{array}$ \\
\hline Control sample & $15.02 \pm 0.19$ & $14.05 \pm 0.24$ & $7.63 \pm 0.11$ \\
\hline Marshmallow - 1\% GSE & $15.21 \pm 0.21$ & $14.11 \pm 0.16$ & $7.80 \pm 0.09$ \\
\hline Marshmallow - 2\% GSE & $15.45 \pm 0.15$ & $14.15 \pm 0.18$ & $7.82 \pm 0.13$ \\
\hline Marshmallow - 3\% GSE & $15.68 \pm 0.23$ & $14.21 \pm 0.22$ & $8.01 \pm 0.08$ \\
\hline
\end{tabular}

The fact that the titratable acidity of marshmallow samples increases from 7.63 to 8.01 with increasing GSE concentration is confirmed by the presence of three major acids in grape skin (Le Moigne et al., 2008). The presence of organic acids from natural plant extracts has been associated with the possibility of extending the shelf life of sugar confections like fruit paste, jelly candy and others (Anand et al., 2013). 


\section{Total Polyphenol content and Antioxidant activity}

In the context of today's nutrition tendency, when people opt for healthier products with a high biological value (Cucinotta, 2018) it is proposed to determine the total polyphenol content and antioxidant effect of obtained marshmallow with added GSE using the value of the ability to inhibit hydrogen peroxide and the DPPH assay.

The values obtained are indicated in Figure 1.

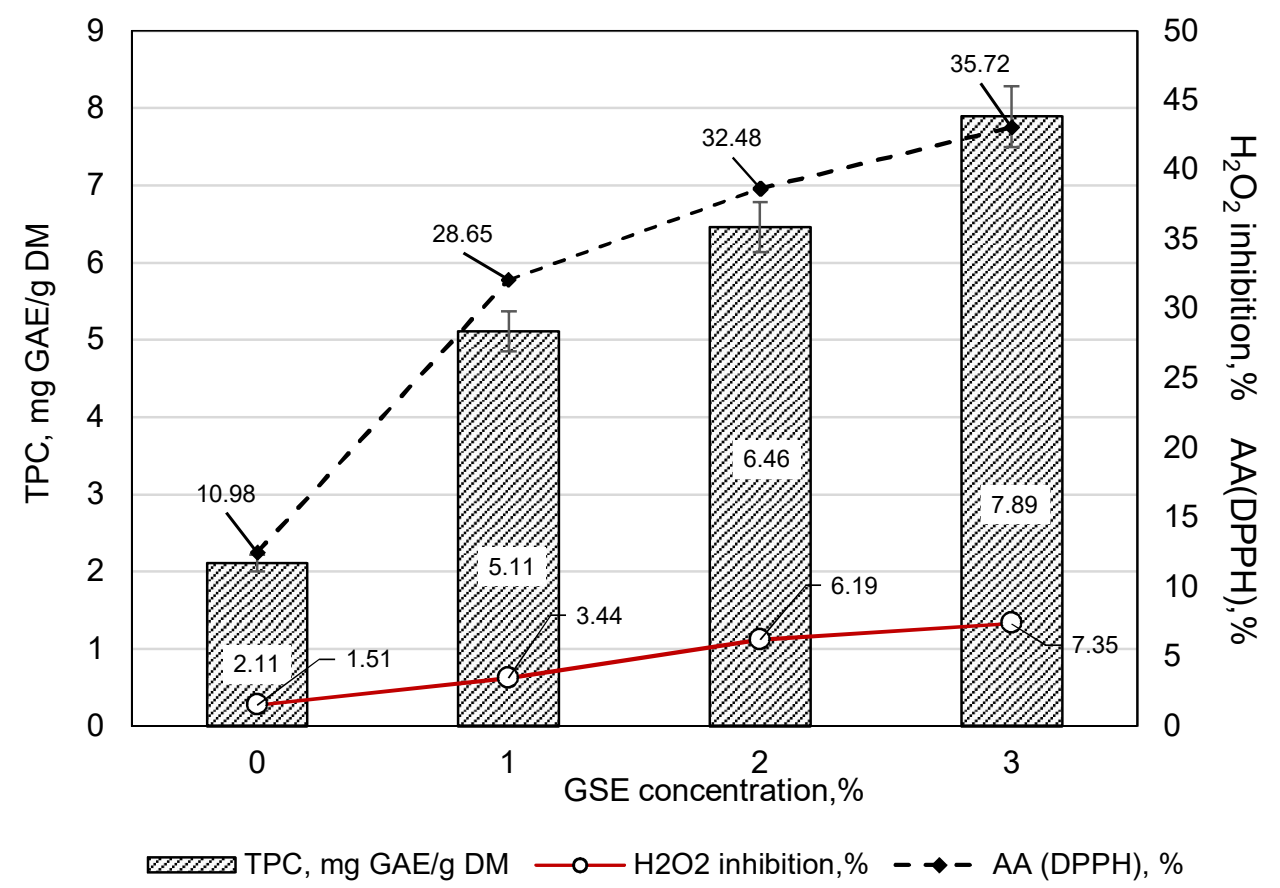

Figure 1. Influence of the total polyphenol content on the antioxidant activity of marshmallow samples

The total content of polyphenols in grape skin powder is $27.39 \pm 0.41 \mathrm{GAE} / \mathrm{g} \mathrm{DM}$, data which are similar to those in the literature, which ranges between $22.2 \pm 9.95 \mathrm{mg} \mathrm{GAE} / \mathrm{g}$ and $45.0 \pm 26.3 \mathrm{mg} \mathrm{GAE} / \mathrm{g}$ depending on grape variety, number of extractions and used solvent (Katalinić et al., 2010; Negro et al., 2003). The incorporation of grape skin in the marshmallow formulation has the effect of increasing the polyphenol content in the investigated samples from $2.11 \pm 0.29 \mathrm{mg} \mathrm{GAE} / \mathrm{g}$ DM for the control sample to $7.89 \pm 0.23$ $\mathrm{mg} \mathrm{GAE} / \mathrm{g}$ DM for the marshmallow sample with 3\% GSE. The same effect of the addition of grape skin on food matrices has been demonstrated in the case of its use in formulations of candies (Cappa et al., 2015; Mutlu et al., 2018), sausages (Ryu et al., 2014), cookies (Acun et al., 2014), etc. In the case of the mentioned products, the positive effect on the total polyphenol content was higher due to the incorporation of GS in the form of powder and not of extract.

In the present study, tests were also performed with the direct use of grape skin powder, but these samples did not have a uniform color distribution, their surface being with purple 
dots, and the consistency was also negatively affected, respectively they have were rejected from a sensory point of view.

The antiradical activity of plants is largely due to polyphenols (Pulido et al., 2000). From the data presented in Figure 1 it can be seen that the amount of polyphenols increases with increasing GSE concentration in the marshmallow samples. At the same time, the amount of polyphenols is directly proportional to the antioxidant activity of the products.

It is known that grape skin has an enormous antioxidant potential (Dordoni et al., 2019). As presented in Figure 1, marshmallow samples with added GSE showed hydrogen peroxide inhibition activity. Many common and life threatening human diseases have free radical reactions as an underlying mechanism of injury. Hydrogen peroxide can cross cell membranes rapidly and form hydroxyl radical and this may be the origin of many toxic effects (Rani et al., 2015). The inhibition of $\mathrm{H}_{2} \mathrm{O}_{2}$ by marshmallow samples with added GSE may at least partly result from its antioxidant and free radical scavenging activity. The $\mathrm{H}_{2} \mathrm{O}_{2}$ inhibition level of marshmallow with $3 \%$ GSE rose to $7.35 \%$ comparing to $1.51 \%$ for control sample.

DPPH is another free radical which is reduced in the presence of an antioxidant molecule. Based on results presented in Figure 1, we can say that as a rule the addition of ethanol grape extract to marshmallow showed higher antioxidant activity values than the control sample. Based on the DPPH assay, the radical scavenging activity of the marshmallow samples with added GSE were $28.65 \pm 0.21 \%$ for the sample with $1 \%$ GSE, $32.48 \pm 0.19 \%$ and $35.72 \pm 0.14 \%$ for the sample with $2 \%$ and $3 \%$ GSE respectively comparing to $10.98 \%$ for the control sample. It worth mentioning that the DPPH radical scavenging activity of the GSE was $89.71 \%$. Rockenbach et al., 2011 mentioned values of 16,925 $3640 \mu \mathrm{mol}$ Trolox equivalents $/ 100 \mathrm{~g}$ for the DPPH assay for different grape varieties (Rockenbach et al., 2011).

\section{Color parameters}

Results concerning the color analysis showed that as a result of the different rates grape skin addition, significant difference was noticed between $L^{*}, a^{*}$ and $b^{*}$ values. Data on the color parameters values $(\mathrm{L}, \mathrm{a}, \mathrm{b})$ of marshmallow are shown in Table 2.

\section{Color parameters values of marshmallow with added grape skin extract}

Table 2

\begin{tabular}{|c|c|c|c|c|}
\hline Sample & $\begin{array}{c}\text { Control } \\
\text { sample }\end{array}$ & $\begin{array}{c}\text { Marshmallow } \\
\mathbf{- 1 \%} \text { GSE }\end{array}$ & $\begin{array}{c}\text { Marshmallow } \\
\mathbf{- 2 \%} \text { GSE }\end{array}$ & $\begin{array}{c}\text { Marshmallow } \\
\mathbf{- 3 \%} \text { GSE }\end{array}$ \\
\hline $\mathbf{L}^{*}$ & $97.56 \pm 1.12$ & $91.00 \pm 0.83$ & $81.27 \pm 0.41$ & $77.13 \pm 0.65$ \\
\hline $\mathbf{a}^{*}$ & $1.21 \pm 0.04$ & $4.32 \pm 0.11$ & $10.44 \pm 0.13$ & $11.52 \pm 0.21$ \\
\hline $\mathbf{b}^{*}$ & $-1.34 \pm 0.03$ & $-4.27 \pm 0.09$ & $-9.31 \pm 0.23$ & $-10.37 \pm 0.17$ \\
\hline $\boldsymbol{\Delta E}$ & - & $7.83 \pm 0.17$ & $20.35 \pm 0.09$ & $24.60 \pm 0.11$ \\
\hline $\mathbf{C}^{*}$ & - & $6.07 \pm 0.06$ & $13.99 \pm 0.13$ & $15.50 \pm 0.09$ \\
\hline $\left.\mathbf{H} \mathbf{(}^{\circ}\right)$ & - & $359.22 \pm 0.01$ & $359.27 \pm 0.01$ & $359.27 \pm 0.01$ \\
\hline
\end{tabular}

As the amount of grape skin increased, a more intense purple coloration of the marshmallow samples was observed. The control sample was white, with $\mathrm{L}^{*}$ value 97 , and tends to decrease by $\mathrm{L}^{*}=77$ for the $3 \%$ GSE sample, this can be explained that at $\mathrm{pH}$ higher than 5 , brightness slightly decreases, indicating that other colored forms are being formed (Chi et al., 2020). On one hand the red - green parameter (a*) also shows an increasing 
tendency, towards a redder shade. This is due to the anthocyanins present in the grape skin, whose color varies in shades of red - blue (Khoo et al., 2017). The same is demonstrated by the decrease of the $b^{*}$ value (blue-yellow), the addition of grape skin giving the products a slightly purple shade. The GSE addition had an influence and on $\Delta \mathrm{E}$ of marshmallow samples, a directly proportional relationship was observed between the increase in GSE addition and the $\Delta \mathrm{E}$ increase. The $\left(\mathrm{C}^{*}\right)$ - chroma parameter shows the color saturation of the marshmallow samples, i.e. indicates the intensity of the purple color relative to white (Milla'n, 2002). The marshmallows with 3\% GSE had a more saturated color. The hue angle $(\mathrm{H})$, is expressed in the scale $00-360^{\circ}$, considered the qualitative attribute of the color, is the attribute according to which the colors have been traditionally defined as reddish, greenish, etc., and is used to define the difference of a certain color with reference to gray with the same lightness. As for GSE marshmallows' hue angle, the addition of GSE did not significantly influence the parameter values, which ranged from 359.22 to $359.22^{\circ}$.

\section{Microbiological stability}

The microbial cells present in the samples to be analyzed on solidified nutrient media formed visible colonies. The total number of mold colonies are shown in Figure 2.

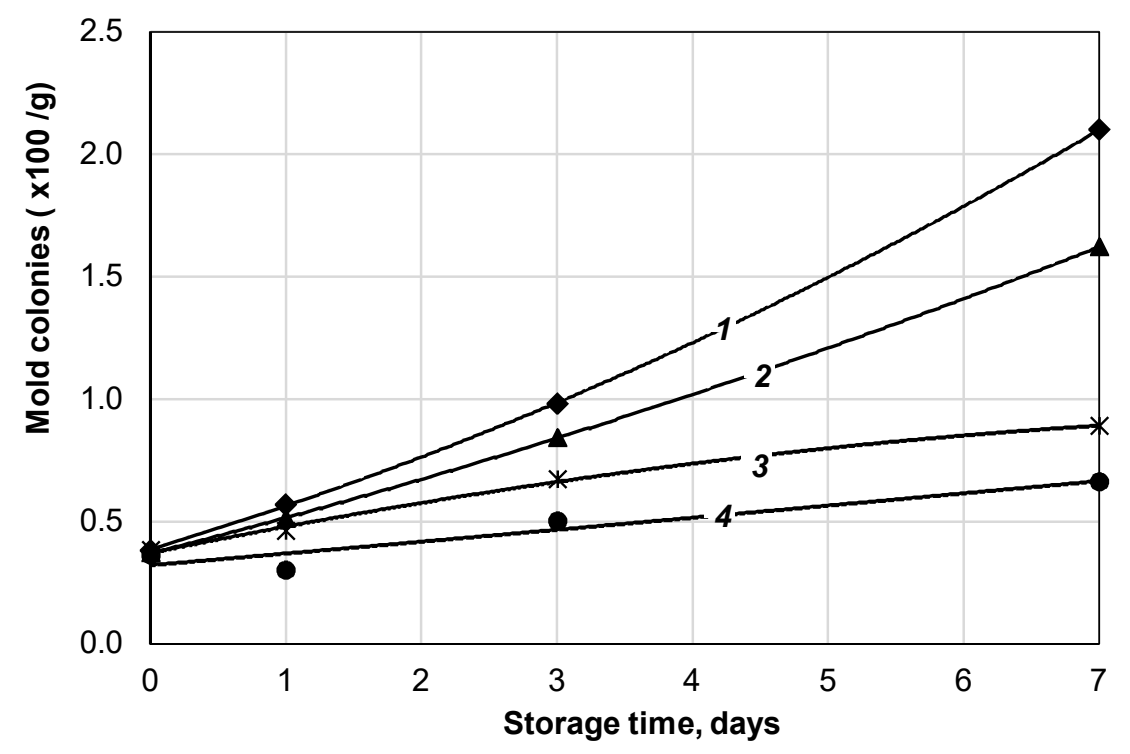

Figure 2. Effect of storage time and grape skin extract addition on microbiological stability of marshmallow.

$\%$ GSE:

$1-0 ; 2-1 ; 3-2 ; 4-3$.

Addition of grape skin extract to marshmallow had inhibitory effects on mould population during storage, a higher degree of mould growth $(p<0.05)$ being observed in the control samples $\left(2.1 \cdot 10^{2}\right.$ colonies $\left./ \mathrm{g}\right)$ as compared to the sample with $3 \%$ added grape skin extract $\left(0.66 \cdot 10^{2} / \mathrm{g}\right)$ i.e. $0.5 \mathrm{log}$ reduction in growth in the sample with $3 \%$ GPE after 7 days 
of storage. The bacteriostatic effect is due to the polyphenols present in the grape skin. The bacteriostatic effect of phenolic compounds has also been demonstrated for Ocimum basilicum Leaves Extracts (Ababutain, 2019), cocoa powder (Pina-Pérez et al., 2017), green tea (Zhang et al., 2020), red raspberry (Nikitina et al., 2007), etc. Concerning grape phenols, their showed an antibacterial effect even at at 1 and 2.5\% concentrations (Furiga et al., 2009; Özkan et al., 2004). Several studies explained the phenols antibacterial activity by the modification of cell membranes permeability (Cushnie et al., 2011), the modification of some intracellular functions induced by hydrogen binding of the phenolic compounds to enzymes (Taguri et al., 2006) or by the modification of the cell wall rigidity with integrity losses due to different interactions between phenols and cell membrane (Negi, 2012).

Length of storage time, showed a concomitant increase in mould population. Seven days storage of control samples increased mould contamination to $0.23 \log$ (Figure 2), indicating an essential effect of storage time on mould growth. The increase of GPE addition to marshmallow formulation showed also a visible effect on mould growth reduction. The main detected mold especies were Aspirgillus versicolor and Penicillium islandicum. The microbiostatic effects of grape skin are also confirmed by previous studies (Hassan et al., 2019).

\section{Sensory evaluation}

Sensory analysis was performed to evaluate the sensory profile of the marshmallow with added grape skin powder extract. The effect of grape skin addition on marshmallow formulation was studied, and 5 quality attributes were evaluated.

Mean scores for liking of color, appearance, flavor (grape notes), taste, texture attributes, and overall liking of samples are presented in Table 3.

Table 3

Mean scores for marshmallow color, appearance, flavor, taste, texture, and overall liking

\begin{tabular}{|l|c|c|c|}
\hline Sample & $\begin{array}{c}\text { Marshmallow - } \\
\text { 1\% GSE }\end{array}$ & $\begin{array}{c}\text { Marshmallow - } \\
\text { 2\% GSE }\end{array}$ & $\begin{array}{c}\text { Marshmallow - } \\
\text { 3\% GSE }\end{array}$ \\
\hline Color & $8.2 \pm 0.23$ & $9.2 \pm 0.24$ & $7.3 \pm 0.32$ \\
\hline Appearance & $7.9 \pm 0.31$ & $9.5 \pm 0.36$ & $7.1 \pm 0.29$ \\
\hline Taste & $8.1 \pm 0.27$ & $8.9 \pm 0.45$ & $8.7 \pm 0.37$ \\
\hline Flavor & $7.7 \pm 0.26$ & $8.9 \pm 0.46$ & $8.1 \pm 0.28$ \\
\hline Texture & $8.4 \pm 0.28$ & $8.4 \pm 0.27$ & $8.3 \pm 0.41$ \\
\hline $\begin{array}{l}\text { Overall } \\
\text { acceptability }\end{array}$ & $8.06 \pm 0.27$ & $8.98 \pm 0.41$ & $7.9 \pm 0.69$ \\
\hline
\end{tabular}

Parameters that were most influenced by the addition of grape skin were color and flavor. Due to the anthocyanin content of the grape skin, the marshmallow samples acquired a shade of purple, which in the case of using 3\% of GSE was too intense, similar to synthetic dyes, for this reason the panelists gave this parameter 7.3 points. In terms of flavor, color and appearance, the most optimal amount of GSE addition would be $2 \%$, in this case the products had a pleasant color and slightly perceived notes of grape flavor. In general, all the tested marshmallow samples obtained scores above 7.0, on a nine-point hedonic scale, and can be considered as acceptable. 


\section{Conclusion}

- The development of marshmallow with grape skin extract is a good strategy to promote the valorization of an industrial waste that has high biological value.

- The formulation of marshmallow with 3\% grape skin extract addition led to the best results in terms of total phenol content, antioxidant capacity, color, texture and general acceptability.

- The fortification with GSE increased the total phenol content and antioxidant activity.

- The addition of grape skin extract also achieved other advantages: the reduction of mold growth during the storage and the delivery of beneficial compounds for human health, promoting in the same time the efficient use of a plant material used to be considered an industrial waste.

Funding. The research was funded by State Project 20.80009.5107.10, nr. PS-62 "Personalized nutrition and intelligent technologies for my well-being", running at Technical University of Moldova.

\section{References}

Ababutain I. (2019), Antimicrobial Activity and Gas Chromatography-Mass Spectrometry (GC-MS) Analysis of Saudi Arabian Ocimum basilicum Leaves Extracts, Journal of Pure and Applied Microbiology, 13(2), pp. 823-833, DOI: 10.22207/JPAM.13.2.17

Abarghuei M. J., Rouzbehan Y., Alipour D. (2010), The influence of the grape pomace on the ruminal parameters of sheep, Livestock Science, 132(1-3), pp. 73-79, DOI: 10.1016/j.livsci.2010.05.002

Acun S., Gül H. (2014), Effects of grape pomace and grape seed flours on cookie quality, Quality Assurance and Safety of Crops \& Foods, 6(1), pp. 81-88, DOI: 10.3920/QAS2013.0264

Anand S. P., Sati N. (2013), Artificial preservatives and their harmful effects: Looking toward nature for safer alternatives, International Journal of Pharmaceutical Sciences and Research, 4(7), pp. 2496-2501.

Antoniolli A., Fontana A. R., Piccoli P., et al. (2015), Characterization of polyphenols and evaluation of antioxidant capacity in grape pomace of the cv. Malbec, Food Chemistry, 178, pp. 172-178, DOI: 10.1016/j.foodchem.2015.01.082

Bordiga M., Travaglia F., Locatelli M. (2019), Valorisation of grape pomace: An approach that is increasingly reaching its maturity - a review, International Journal of Food Science \& Technology, 54(4), pp. 933-942, DOI: 10.1111/ijfs.14118

Caldas T. W., Mazza K. E. L., Teles A. S. C., et al. (2018), Phenolic compounds recovery from grape skin using conventional and non-conventional extraction methods, Industrial Crops and Products, 111, pp. 86-91, DOI: 10.1016/j.indcrop.2017.10.012

Caleja C., Barros L., Antonio A. L., et al. (2017), A comparative study between natural and synthetic antioxidants: Evaluation of their performance after incorporation into biscuits, Food Chemistry, 216, pp. 342-346, DOI: 10.1016/j.foodchem.2016.08.075

Cano-Lamadrid M., Vázquez-Araújo L., Sánchez-Rodríguez L., et al. (2018), Consumers' Opinion on Dried Pomegranate Arils to Determine the Best Processing 
Conditions, Journal of Food Science, 83(12), pp. 3085-3091, DOI: 10.1111/17503841.14390

Cappa C., Lavelli V., Mariotti M. (2015), Fruit candies enriched with grape skin powders: Physicochemical properties, LWT - Food Science and Technology, 62(1), pp. 569575, DOI: 10.1016/j.lwt.2014.07.039

Chi W., Cao L., Sun G., et al. (2020), Developing a highly pH-sensitive K-carrageenanbased intelligent film incorporating grape skin powder via a cleaner process, Journal of Cleaner Production, 244, 118862, DOI: 10.1016/j.jclepro.2019.118862

Cucinotta D. (2018), Preparing for the Decade of Healthy Aging (2020-2030): Prevention plus therapy? Acta Bio Medica Atenei Parmensis, 89(2), pp. 145-147, DOI: 10.23750/abm.v89i2.7402

Cushnie T. P. T., Lamb A. J. (2011), Recent advances in understanding the antibacterial properties of flavonoids, International Journal of Antimicrobial Agents, 38(2), pp. 99-107, DOI: 10.1016/j.ijantimicag.2011.02.014

Cvjetko Bubalo M., Ćurko N., Tomašević M., et al. (2016), Green extraction of grape skin phenolics by using deep eutectic solvents, Food Chemistry, 200, pp. 159-166, DOI: 10.1016/j.foodchem.2016.01.040

Dordoni R., Cantaboni S., Spigno G. (2019), Walnut paste: Oxidative stability and effect of grape skin extract addition, Heliyon, 5(9), e02506, DOI: 10.1016/j.heliyon.2019.e02506

dos Santos K. M., de Oliveira I. C., Lopes M. A., et al. (2017), Addition of grape pomace extract to probiotic fermented goat milk: The effect on phenolic content, probiotic viability and sensory acceptability: Grape pomace extract effect on fermented goat milk, Journal of the Science of Food and Agriculture, 97(4), pp. 1108-1115, DOI: 10.1002/jsfa.7836

Ergun R., Lietha R., Hartel R. W. (2010), Moisture and Shelf Life in Sugar Confections, Critical Reviews in Food Science and Nutrition, 50(2), pp. 162-192, DOI: 10.1080/10408390802248833

Furiga A., Lonvaud-Funel A., Badet C. (2009), In vitro study of antioxidant capacity and antibacterial activity on oral anaerobes of a grape seed extract, Food Chemistry, 113(4), pp. 1037-1040, DOI: 10.1016/j.foodchem.2008.08.059

Goñi S. M., Salvadori V. O. (2017), Color measurement: Comparison of colorimeter vs. computer vision system, Journal of Food Measurement and Characterization, 11(2), pp. 538-547, DOI: 10.1007/s11694-016-9421-1

Gustavsson J., Cederberg C., Sonesson U. (2011), Global food losses and food waste: Extent, causes and prevention ; study conducted for the International Congress Save Food! at Interpack 2011, [16-17 May], Düsseldorf, Germany. Food and Agriculture Organization of the United Nations

Hassan Y. I., Kosir V., Yin X., et al. (2019), Grape Pomace as a Promising Antimicrobial Alternative in Feed: A Critical Review, Journal of Agricultural and Food Chemistry, 67(35), pp. 9705-9718, DOI: 10.1021/acs.jafc.9b02861

Horwitz W. (Ed.), (2005), Official methods of analysis of AOAC International (18. ed). AOAC International

Iora S. R. F., Maciel G. M., Zielinski A. A. F., et al. (2015), Evaluation of the bioactive compounds and the antioxidant capacity of grape pomace, International Journal of Food Science \& Technology, 50(1), pp. 62-69, DOI: 10.1111/ijfs. 12583

Jariyapamornkoon N., Yibchok-anun S., Adisakwattana S. (2013), Inhibition of advanced glycation end products by red grape skin extract and its antioxidant activity, $B M C$ Complementary and Alternative Medicine, 13(1), p. 171, DOI: 10.1186/1472-6882-13-171 
Jung J. H., Lee J. E. (2016), Real-time bacterial microcolony counting using on-chip microscopy, Scientific Reports, 6(1), 21473, DOI: 10.1038/srep21473

Katalinić V., Možina S. S., Skroza D., et al. (2010), Polyphenolic profile, antioxidant properties and antimicrobial activity of grape skin extracts of 14 Vitis vinifera varieties grown in Dalmatia (Croatia), Food Chemistry, 119(2), pp. 715-723, DOI: 10.1016/j.foodchem.2009.07.019

Khoo H. E., Azlan A., Tang S. T., et al. (2017), Anthocyanidins and anthocyanins: Colored pigments as food, pharmaceutical ingredients, and the potential health benefits, Food \& Nutrition Research, 61(1), 1361779, DOI: 10.1080/16546628.2017.1361779

Kumar C. C., Mythily R., Venkatachalapathy R., et al. (2014), Bio-mimic conversion of Maida (polysaccharides) to reducing sugars by acid hydrolysis and its estimation using standard methods, International Food Research Journal, 21((2)), pp. 523-526.

Le Moigne M., Maury C., Bertrand D., et al. (2008), Sensory and instrumental characterisation of Cabernet Franc grapes according to ripening stages and growing location, Food Quality and Preference, 19(2), pp. 220-231, DOI: 10.1016/j.foodqual.2007.03.004

Ly B. C. K., Dyer E. B., Feig J. L., et al. (2020), Research Techniques Made Simple: Cutaneous Colorimetry: A Reliable Technique for Objective Skin Color Measurement, Journal of Investigative Dermatology, 140(1), 3-12.e1, DOI: 10.1016/j.jid.2019.11.003

Makkar H. P. S. (2003), Measurement of Total Phenolics and Tannins Using FolinCiocalteu Metho, In H. P. S. Makkar, Quantification of Tannins in Tree and Shrub Foliage, pp. 49-51, Springer Netherlands, DOI: 10.1007/978-94-017-0273-7_3

McGuire S. (2013), WHO, World Food Programme, and International Fund for Agricultural Development. 2012. The State of Food Insecurity in the World 2012. Economic growth is necessary but not sufficient to accelerate reduction of hunger and malnutrition, Rome, FAO, Advances in Nutrition, 4(1), pp. 126-127, DOI: 10.3945/an.112.003343

Milla'n M. S. (2002), Color pattern recognition with CIELAB coordinates, Optical Engineering, 41(1), 130, DOI: 10.1117/1.1428295

Mutlu C., Tontul S. A., Erbaş M. (2018), Production of a minimally processed jelly candy for children using honey instead of sugar, LWT, 93, pp. 499-505, DOI: 10.1016/j.lwt.2018.03.064

Nagulendran Kr., Velavan S., Mahesh R., et al. (2007), In vitro Antioxidant Activity and Total Polyphenolic Content of Cyperus rotundus Rhizomes, E-Journal of Chemistry, 4(3), pp. 440-449, DOI: 10.1155/2007/903496

Negi P. S. (2012), Plant extracts for the control of bacterial growth: Efficacy, stability and safety issues for food application, International Journal of Food Microbiology, 156(1), pp. 7-17, DOI: 10.1016/j.ijfoodmicro.2012.03.006

Negro C., Tommasi L., Miceli, A. (2003), Phenolic compounds and antioxidant activity from red grape marc extracts, Bioresource Technology, 87(1), pp. 41-44, DOI: 10.1016/S0960-8524(02)00202-X

Nikitina V. S., Kuz'mina L. Yu., Melent'ev A. I., et al. (2007), Antibacterial activity of polyphenolic compounds isolated from plants of Geraniaceae and Rosaceae families, Applied Biochemistry and Microbiology, 43(6), pp. 629-634, DOI: 10.1134/S0003683807060117

Oiv-statistical-report-on-world-vitiviniculture-2018.pdf. (n.d.).

Otero-Pareja M., Casas L., Fernández-Ponce M., et al. (2015), Green Extraction of Antioxidants from Different Varieties of Red Grape Pomace, Molecules, 20(6), pp. 96869702, DOI: $10.3390 /$ molecules 20069686 
Özkan G., Sagdiç O., Göktürk Baydar N., et al. (2004), Antibacterial activities and total phenolic contents of grape pomace extracts, Journal of the Science of Food and Agriculture, 84(14), pp. 1807-1811, DOI: 10.1002/jsfa. 1901

Pina-Pérez M. C., Rivas A., Martínez A., et al. (2017), Antimicrobial potential of macro and microalgae against pathogenic and spoilage microorganisms in food, Food Chemistry, 235, pp. 34-44, DOI: 10.1016/j.foodchem.2017.05.033

Pulido R., Bravo L., Saura-Calixto F. (2000), Antioxidant Activity of Dietary Polyphenols As Determined by a Modified Ferric Reducing/Antioxidant Power Assay, Journal of Agricultural and Food Chemistry, 48(8), pp. 3396-3402, DOI: 10.1021/jf9913458

Rani, V., Yadav, U. C. S. (Eds.). (2015), Free Radicals in Human Health and Disease, Springer India, DOI: 10.1007/978-81-322-2035-0

Rockenbach I. I., Gonzaga L. V., Rizelio V. M., et al. (2011), Phenolic compounds and antioxidant activity of seed and skin extracts of red grape (Vitis vinifera and Vitis labrusca) pomace from Brazilian winemaking, Food Research International, 44(4), pp. 897-901, DOI: 10.1016/j.foodres.2011.01.049

Ryu K. S., Shim K. S., Shin D. (2014), Effect of Grape Pomace Powder Addition on TBARS and Color of Cooked Pork Sausages during Storage, Korean Journal for Food Science of Animal Resources, 34(2), pp. 200-206, DOI: 10.5851/kosfa.2014.34.2.200

Sharma O. P., Bhat T. K. (2009), DPPH antioxidant assay revisited, Food Chemistry, 113(4), pp. 1202-1205, DOI: 10.1016/j.foodchem.2008.08.008

Shin M.-O., Moon J.-O. (2010), Effect of dietary supplementation of grape skin and seeds on liver fibrosis induced by dimethylnitrosamine in rats, Nutrition Research and Practice, 4(5), 369, DOI: 10.4162/nrp.2010.4.5.369

Sun T., Chen Q. Y., Wu L. J., et al. (2012), Antitumor and antimetastatic activities of grape skin polyphenols in a murine model of breast cancer, Food and Chemical Toxicology, 50(10), pp. 3462-3467, DOI: 10.1016/j.fct.2012.07.037

Taghvaei M., Jafari, S. M. (2015), Application and stability of natural antioxidants in edible oils in order to substitute synthetic additives, Journal of Food Science and Technology, 52(3), pp. 1272-1282, DOI: 10.1007/s13197-013-1080-1

Taguri T., Tanaka T., Kouno I. (2006), Antibacterial Spectrum of Plant Polyphenols and Extracts Depending upon Hydroxyphenyl Structure, Biological and Pharmaceutical Bulletin, 29(11), pp. 2226-2235, DOI: 10.1248/bpb.29.2226

Theagarajan R., Malur Narayanaswamy L., Dutta S. et al. (2019), Valorisation of grape pomace (cv. Muscat) for development of functional cookies, International Journal of Food Science \& Technology, 54(4), pp. 1299-1305, DOI: 10.1111/ijfs.14119

Ungure E., Straumīte E., Muižniece-Brasava S. et al. (2013), Consumer Attitude and Sensory Evaluation of Marshmallow, Proceedings of the Latvian Academy of Sciences. Section B. Natural, Exact, and Applied Sciences, 67(4-5), pp. 442-447, DOI: 10.2478/prolas2013-0077

Yurchenko D., Polovyk V., Koretska I. (2020), The use of non-traditional raw materials in the technology of whipped dessert, Annals of 59th Science Conference of Ruse University, Bulgaria, pp. 18-23.

Zhang J., Tao M., Huang Z., et al. (2020), Significant effects of two pesticides on the bacteriostatic activity and antioxidant ability of green tea polyphenols, RSC Advances, 10(43), pp. 25662-25668, DOI: 10.1039/D0RA02807J 